DOI 10.51522/2307-0382-2021-230-7-6-14

УДК 343.8

\title{
Ф. В. ГРУШИН
}

профессор кафедры уголовно-исполнительного права Академии ФСИН России, доктор юридических наук, доцент, полковник внутренней службы

Рязань

\section{FEDOR. V. GRUSHIN}

Professor of the Department of Penal Law of the Academy of the FPS of Russia, Doctor of Law, Associate Professor, Colonel of the Internal Service

Ryazan

\section{Развитие уголовной политики в отношении условно-досрочного освобождения от отбывания наказания}

\author{
Development of criminal policy in relation to parole \\ from serving a sentence
}

\begin{abstract}
Аннотация. В статье рассматриваются некоторые аспекты развития института условно-досрочного освобождения от отбывания наказания.

Цель научного исследования: разработка предложений в сфере правового регулирования условно-досрочного освобождения осужденных от отбывания наказания. Научная значимость работы состоит в теоретико-правовом анализе развития уголовно-правовой и уголовно-исполнительной политики Российской Федерации в сфере условно-досрочного освобождения. Практическая значимость работы заключается в разработке предложений, позволяющих повысить эффективность реализации рассматриваемого института. Методы исследования: историко-правовой, сравнительно-правовой, формально-юридический, конкретно-социологический и другие.
\end{abstract}

Abstract. The article examines some development aspects of the institution of parole from serving a sentence.

The purpose of the research: development of proposals in the field of legal regulation of parole of convicts from serving their sentences. The scientific importance of the work lies in the theoretical and legal analysis of the development of the criminallegal and penal policy of the Russian Federation in the field of parole. The practical significance of the work lies in the development of proposals to improve the efficiency of implementing the institution under consideration. Research methods: historical-legal, comparative-legal, formal-legal, specific sociological and others.

Main results, conclusions of the research work: the need to establish the right of institutions and bodies executing punishment to independently submit to the court documents on the parole of 
Основные результаты, выводы исследовательской работы: обосновывается необходимость установления права учреждений и органов, исполняющих наказания, самостоятельно направлять в суд представления об условно-досрочном освобождении осужденных в порядке их поощрения; определены некоторые проблемы, связанные с возложением на уголовно-исполнительные инспекции функции контроля за лицами, освобожденными условно-досрочно; проанализированы критерии предоставления условно-досрочного освобождения; обосновано предложение о введении пенитенциарных судей (судов) и прочее. Данная научная работа может внести вклад в развитие уголовного и уголовно-исполнительного права, в практическую деятельность судов, а также учреждений и органов, исполняющих уголовные наказания.

Ключевые слова: условно-досрочное освобождение, осужденные, уголовно-правовая политика, уголовно-исполнительная политика, пенитенциарные судьи. convicts as the means of their encouragement is substantiated; some problems related to the assignment of the function of control over persons released on parole to the penitentiary inspectorates are identified; the criteria for granting parole are analyzed; the proposal to introduce penitentiary judges (courts) is substantiated, and so on. This scientific work can contribute to the development of criminal and penal law, to the practical activities of courts, as well as institutions and bodies that execute criminal sentences.

Key words: parole, convicts, criminal law policy, criminal executive policy, penitentiary judges.

12.00.08 Уголовное право и криминология; уголовно-исполнительное право (юридические науки) Criminal Law and Criminology; penal law (legal sciences)

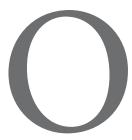
дним из отраслевых принципов уголовно-исполнительного законодательства Российской Федерации является принцип стимулирования правопослушного поведения осужденных. Как показывает многолетняя практика учреждений и органов, исполняющих наказания, условно-досрочное освобождение от отбывания наказания (УДО) является если не самым эффективным, то одним из самых эффективных средств стимулирования правопослушного поведения осужденных. Примерно такие же выводы содержатся и в специальных международных актах, касающихся обращения с осужденными. Так, согласно рекомендации № $\operatorname{Rec}(2003) 22$ Комитета министров Coвета Европы «Об условно-досрочном освобождении» (принята 24.09.2003 на 853-м заседании представителей министров), УДО «является одним из самых эффективных и действенных способов предупреждения повторного совершения преступлений, способствующих возвращению в общество заключенного путем его планомерной и контролируемой ресоциализации».

Перспектива УДО способствует тому, что осужденные стремятся трудоустроиться, соблюдать режимные требования, возмещать вред, причиненный преступлением, участвовать в проводимых воспитательных мероприятиях и совершать иные позитивные действия, способствующие их исправлению. Но при положительной оценке данного института в целом все-таки существует вероятность того, что осужденные могут целенаправленно добиваться нужных показателей для до- 
стижения УДО. С одной стороны, это негативный момент, так как осужденные в данной ситуации занимаются приспособленчеством, а с другой - в любом случае со стороны осужденных совершаются позитивные действия, что будет в конечном счете способствовать их исправлению.

Развитие уголовной политики* в отношении условно-досрочного освобождения от отбывания наказания в Российской Федерации шло весьма разновекторно. Если уголовно-правовая политика в большей степени ужесточалась (увеличивались сроки фактического отбытия наказания, после которых возможно предоставление УДО, в отношении отдельных категорий осужденных; вводились дополнительные критерии и условия, без выполнения которых невозможно было получить условно-досрочное освобождение; усложнялась процедура УДО и прочее), то уголовно-исполнительная политика корректировалась в меньшей степени и в основном смягчалась по отношению к осужденному. Усложнение процедуры УДО по уголовно-исполнительному законодательству осуществлялось в подавляющем большинстве случаев в результате соответствующих изменений уголовно-правовой политики (например, ужесточение в отношении лиц, совершающих преступления против половой неприкосновенности несовершеннолетних, приводило к изменениям уголовно-исполнительного законодательства в части усложнения процедуры оформления УДО для данной категории осужденных). Вместе с тем необходимо добавить, что уголовно-правовая политика в отношении УДО несовершеннолетних осужденных на

* Под уголовной политикой подразумевается в целом политика в сфере борьбы с преступностью, составными частями которой являются уголовно-правовая, уголовно-исполнительная, уголовно-процессуальная и иные виды политики. В рамках данной статьи сделан акцент на уголовно-правовой и уголовно-исполнительной политике. всем протяжении своего развития исключительно смягчалась.

Одно из самых значимых изменений в институте УДО произошло в 2003 году. В результате данных изменений осужденный, а также его адвокат (законный представитель) были наделены правом самостоятельного обращения в суд с ходатайством об УДО (Федеральный закон «О приведении Уголовно-процессуального кодекса Российской Федерации и других законодательных актов в соответствие с Федеральным законом „О внесении изменений и дополнений в Уголовный кодекс Российской Федерации“» от 08.12.2003 № 161-Ф3). Положительно оценивая эти изменения в целом, все-таки необходимо отметить, что одновременно была изменена и норма статьи 113 Уголовно-исполнительного кодекса Российской Федерации (УИК РФ), в которой из перечня мер поощрения, применяемых к осужденным к лишению свободы, была исключена возможность представления администрацией исправительного учреждения осужденного к УДО. Аналогичные изменения были внесены и в статью 167 УИК РФ, в которой регулируется применение мер поощрения к осужденным военнослужащим, содержащимся в дисциплинарных воинских частях. В результате в настоящее время исправительные учреждения не наделены правом самостоятельно направлять в суд представления об условно-досрочном освобождении осужденных в порядке их поощрения. Не совсем понятна позиция законодателя по данному вопросу, так как ничто не мешало сохранить обе процедуры представления к УДО. Полагаем, что в целях стимулирования правопослушного поведения осужденных данные нормы в статьях 113 и 167 УИК РФ следовало бы вернуть. Кроме того, в целях большей заинтересованности осужденных в правопо- 
слушном поведении в период отбывания наказания возможно даже каким-то образом отделить представление администрации к УДО от ходатайства самих осужденных. Например, администрация в отношении наиболее положительно характеризующихся осужденных могла бы выходить в суд с представлением об УДО несколько раньше, чем это установлено в отношении ходатайства, подаваемого осужденным или его законным представителем.

Что касается последних изменений уголовной политики в отношении УДО, то они связаны с обеспечением прав потерпевшего, нарушенных в результате преступления. Данные изменения сводятся в основном к уведомлению потерпевшего или его законного представителя о возможном досрочном освобождении осужденного. Кроме того, сохраняется начатый еще в 90-х годах прошлого века курс на гуманизацию уголовной политики. Так, в 2020 году статья 79 Уголовного кодекса Российской Федерации (УК РФ) была дополнена частью $3^{1}$, в которой было установлено право отдельных категорий осужденных женского пола претендовать на УДО по отбытии одной четверти срока наказания.

Наконец, в марте 2021 года произошло изменение, которого ученые (с надеждой), а практики (с опасением) ждали на протяжении более 20 лет. С момента принятия в 1996 году Уголовного кодекса Российской Федерации часть 6 статьи 79 предусматривала, что контроль за поведением лица, освобожденного условно-досрочно, осуществляется уполномоченным на то специализированным государственным органом. Однако до последнего времени такой орган так и не был определен, то есть законодателем был предусмотрен контроль за лицами, освобожденными условно-досрочно, но при этом он прак- тически не осуществлялся. И вот Указом Президента Российской Федерации от 02.03.2021 № 119 «О внесении изменений в Положение о Федеральной службе исполнения наказаний, утвержденное Указом Президента Российской Федерации от 13 октября 2004 г. № 1314» на ФСИН России (в частности, на уголовно-исполнительные инспекции) была возложена функция по контролю за поведением лиц, освобожденных условно-досрочно от отбывания наказания. С точки зрения практической необходимости данное решение требовалось с момента принятия УК РФ, так как целесообразность осуществления контроля за рассматриваемой категорией лиц не вызывает сомнений, однако с точки зрения его реализации на практике возникнет множество вопросов.

Во-первых, как следует из указа президента, штатная численность работников учреждений, исполняющих наказания, следственных изоляторов и иных входящих в уголовно-исполнительную систему учреждений и организаций остается неизменной, то есть дополнительная нагрузка, а это порядка 40-50 тысяч осужденных, освобождающихся условно-досрочно ежегодно, ляжет на плечи уголовно-исполнительных инспекций без увеличения их штатной численности, что вряд ли будет способствовать осуществлению ими эффективного контроля. Возможно, что случится перераспределение штатной численности во ФСИН России за счет снижения количества исправительных учреждений в пользу инспекций, так как в последнее время происходит ежегодное существенное сокращение осужденных к лишению свободы, однако даже в этом случае потребуется время для переобучения бывших сотрудников исправительных учреждений, переведенных для дальнейшего прохождения службы в инспекции. Во-вторых, пока 
не приняты ведомственные нормативные правовые акты, регулирующие порядок осуществления контроля инспекциями за поведением лиц, освобожденных условно-досрочно, что также в первое время будет негативно сказываться на практике реализации инспекциями рассматриваемой функции.

В целом необходимо отметить, что развитие института УДО проходит достаточно планомерно, возникающие проблемы законодателем постепенно решаются. Так, в частности, в 2014 году часть $4^{1}$ статьи 79 УК РФ была существенно расширена за счет установления различных критериев для УДО. Вместе с тем на практике при реализации рассматриваемого института возникает множество проблем, требующих обсуждения и решения. Среди них исследователи выделяют следующие:

- установление новых критериев и условий для предоставления УДО $[1,2,3]$;

- особенности реализации УДО в отношении лиц, осужденных к пожизненному лишению свободы [4];

- отличающаяся в схожих случаях судебная практика [5];

- процедура прохождения УДО $[6,7]$;

- коррупционные риски [8] и ряд других.

Не совсем понятна позиция законодателя, устанавливающая, что УДО может быть применено только в отношении наказания в виде лишения свободы, содержания в дисциплинарной воинской части и принудительных работ. До принятия Федерального закона от 08.12.2003 № 162-Ф3 «О внесении изменений и дополнений в Уголовный кодекс Российской Федерации» УК РФ предусматривал возможность УДО также и в отношении осужденных, отбывающих наказания в виде исправительных работ, ограничения по военной службе и ограничения свободы. Нет соответству- ющего комментария и в пояснительной записке к проекту данного федерального закона, так как первоначальная редакция проекта не предусматривала отмены возможности УДО при исправительных работах, ограничении по военной службе и ограничении свободы.

С учетом крайне высокого стимулирующего эффекта УДО полагаем, что оно может и должно применяться в отношении таких действующих в настоящее время наказаний, как лишение права занимать определенные должности или заниматься определенной деятельностью, обязательные работы, исправительные работы, ограничение по военной службе и ограничение свободы. Реализация данной инициативы позволит более эффективно достигать основной цели наказания - исправления осужденных.

В поддержку этого предложения можно привести опыт ряда зарубежных стран, а также существующие международные документы.

Например, статья 72 Уголовного кодекса Республики Казахстан предусматривает возможность УДО в отношении осужденных, отбывающих ограничение свободы (аналог обязательных работ в Российской Федерации). Еще больше возможностей для УДО предусмотрено уголовным законодательством Республики Беларусь. Так, статья 90 Уголовного кодекса Республики Беларусь предусматривает возможность УДО для лиц, отбывающих альтернативные наказания в виде лишения права занимать определенные должности или заниматься определенной деятельностью, исправительных работ, ограничения по военной службе, ограничения свободы (аналог принудительных работ и ограничения свободы в Российской Федерации). Достаточно широкий круг альтернативных наказаний, при которых возможно 
применение УДО, существует и в Украине. Статья 81 Уголовного кодекса Украины предусматривает применение УДО к лицам, отбывающим наказания в виде исправительных работ, служебных ограничений для военнослужащих (аналог ограничения по военной службе в Российской Федерации), ограничения свободы (аналог принудительных работ в Российской Федерации).

Кроме того, такой важнейший международный документ в отношении реализации наказаний, не связанных с изоляцией от общества, как Минимальные стандартные правила Организации Объединенных Наций в отношении мер, не связанных с тюремным заключением (Токийские правила), в пункте 9.2 предусматривает, что положения, действующие после вынесения приговора, могут включать сокращение срока наказания.

В контексте рассматриваемого вопроса также возможно поддержать идею В. С. Епанешникова [9], В. М. Лебедева [10], В. Руднева [11] о введении в судебной системе так называемых пенитенциарных судей. Как уже было сказано, одной из проблем при реализации института УДО является разноплановая судебная политика при вынесении судом решений по условно-досрочному освобождению. Как нам представляется, одной из причин сложившейся ситуации является то, что для судей вопросы, связанные с особенностями отбывания наказания, не являются профильными, а в некоторых случаях носят некий факультативный характер. Пенитенциарные судьи могли бы в большей степени погрузиться в особенности исполнения наказания, основательно изучить личность осужденного, его поведение, социальные связи. Кроме того, данные судьи были бы в постоянном контакте с учреждениями и органами, исполняющими наказания, что также способствовало бы более объективному (неформальному) вынесению судебных решений. Помимо УДО пенитенциарные судьи могли бы рассматривать в отношении осужденных, отбывающих наказание, следующие вопросы:

- замена неотбытой части наказания более мягким видом наказания;

- изменение вида исправительного учреждения;

- отсрочка отбывания наказания;

- освобождение от отбывания наказания в связи с болезнью;

- установление административного надзора за лицами, освобождаемыми из мест лишения свободы;

- жалобы осужденных и прочие.

Идею о введении должности специализированного судьи в некоторых случаях поддерживают и сами судьи, например Д. А. Давыдов [12]. С точки зрения решения вопросов на стадии исполнения приговора, а также регулирования уголовно-процессуальных отношений данную идею поддерживают и некоторые ученые $[13,14]$. Кроме того, в разных странах существуют специальные пенитенциарные суды. Например, А. В. Шашкова сообщает, что в Испании успешно функционируют специализированные Центральные пенитенциарные суды [15].

Таким образом, представляется возможным и необходимым внедрение в отечественную судебную систему пенитенциарных судей или пенитенциарных судов.

Отдельно следует остановиться на критериях, которые необходимо учитывать суду при предоставлении УДО. Определенные в законе критерии, по нашему мнению, содержат в себе некоторые недостатки. Так, в частности, в пункте $4^{1}$ статьи 79 УК РФ установлено такое общее основание условно-досрочного освобождения осужденного, как «заключение администрации исправительного учреждения о 
целесообразности его условно-досрочного освобождения». Однако статья 79 УК РФ предусматривает УДО в отношении лиц, осужденных не только к лишению свободы. Получается, что на основании статьи 79 УК РФ заключение администрации исправительного центра (дисциплинарной воинской части) о целесообразности УДО осужденных к принудительным работам (содержанию в дисциплинарной воинской части) суду не требуется? Однако это не так, ведь на основании части 2 статьи 175 Уголовно-исполнительного кодекса Российской Федерации (УИК РФ) администрация учреждения (в том числе и исправительного центра, и дисциплинарной воинской части), исполняющего наказание, обязана направить в суд ходатайство осужденного об условно-досрочном освобождении от отбывания наказания вместе с характеристикой, в которой должно содержаться заключение о целесообразности УДО. Таким образом, в пункте $4^{1}$ статьи 79 УК РФ вместо «заключения администрации исправительного учреждения» необходимо указать «заключение администрации учреждения, исполняющего наказание, в котором осужденный отбывает наказание».

Также не совсем верно, что законодательство содержит достаточно большое количество абстрактных (недостаточно определенных) критериев применения условно-досрочного освобождения, таких как, например, раскаяние осужденного в совершенном деянии, поведение осужденного, иные сведения, свидетельствующие об исправлении осужденного. Мы согласны с Д. В. Савельевым в том, что в результате судьи при вынесении решений об УДО по свому усмотрению интерпретируют те или иные критерии, что в некоторых случаях приводит к негативным последствиям, а также трудностям в пра- воприменительной практике, осуществляемой судами [5].

Среди ученых периодически высказываются идеи по совершенствованию существующей системы. Например, Ю. А. Кашуба и А. П. Скиба предлагают ввести новый критерий применения УДО - отношение осужденного к своему здоровью, что способствовало бы снижению фактов членовредительства [1]. В целом возможно оценить этот критерий положительно, однако он также носит достаточно абстрактный характер, что может привести к неоднозначному толкованию в суде. Так же как крайне абстрактный, хотя и детально проработанный с научной точки зрения, возможно рассматривать такой критерий, как общественная безопасность осужденного, предложенный Б. Т. Разгильдиевым [2] и И. А. Ефремовой [3].

Достаточно трудно согласиться с И. А. Давыдовой и И. Н. Коробовой, которые предлагают полностью исключить возможность УДО для некоторых категорий осужденных, например для лиц, совершивших отдельные виды особо тяжких преступлений [7]. Также весьма дискуссионно предложение Д. Лебедевича, который отмечает, что наличие у осужденного пяти погашенных судимостей вполне может быть основанием для отказа в предоставлении условно-досрочного освобождения [16].

Полагаем, что окончательно лишать осужденных перспективы УДО не совсем верно, так как в этом случае возникнут трудности с достижением целей наказания.

Таким образом, рассматриваемый институт УДО нуждается в дальнейшем анализе и развитии по следующим направлениям:

- наделение администраций учреждений, исполняющих наказания, правом 
вынесения в суд представлений об УДО в отношении положительно характеризующихся осужденных;

- расширение круга критериев для рассмотрения вопроса об УДО в суде, а также отказ от абстрактных субъективных критериев;

- введение института пенитенциарных судей (пенитенциарных судов), которые рассматривали бы вопросы, связанные с процессом исполнения уголовных наказаний и иных мер уголовно-правового характера;

- возможность применения УДО в отношении осужденных к наказаниям, не связанным с изоляцией от общества;

- подготовка и принятие ведомственных актов, регулирующих порядок осуществления контроля за лицами, освобожденными условно-досрочно. $\diamond$

1. Кашуба Ю. А., Скиба А. П. Институт условно-досрочного освобождения: новый взгляд // Человек: преступление и наказание. 2011. № 1. С. 14-17.

2. Разгильдиев Б. Т. Уголовно-правовое предупреждение незаконного оборота наркотических средств и психотропных веществ, виды и критерии реализации // Уголовно-правовая превенция в сфере оборота наркотических средств или психотропных веществ, алкогольной и спиртосодержащей продукции (региональный аспект) : сборник материалов Всероссийской научно-практической конференции (Чебоксары, 17 апр. 2015 г.). Чебоксары : Изд-во Чувашского университета, 2015. С. 250-260.

3. Ефремова И. А. Материальное основание условно-досрочного освобождения от наказания // Всероссийский криминологический журнал. 2018. Т. 12, № 1. С. 82-91.

4. Князьков А. С., Уткин В. А. Условно-досрочное освобождение при пожизненном лишении свободы // Вестник Томского государственного университета. Право. 2015. № 4. С. 45-53.

5. Савельев Д. В. Основания и условия освобождения от уголовной ответственности и наказания : учебное пособие для вузов. М. : Юрайт, 2020. 191 с.

6. Бабаян С. Л. К вопросу о применении поощрительного института условно-досрочного освобождения от отбывания наказания // Вестник Московского государственного лингвистического университета. Образование и педагогические науки. 2017. № 3. С. 142-149.

7. Давыдова И. А., Коробова И. Н. К вопросу об эффективности института условно-досрочного освобождения // Ведомости уголовно-исполнительной системы. 2017. № 12. С. 20-25.

8. Мяханова А. Н., Синьков Д. В. К вопросу о коррупции при условно-досрочном освобождении // Вестник Омской юридической академии. 2018. Т. 15, № 3. С. 292-297.

9. Епанешников В. С. Юридическая ответственность лиц, отбывающих наказание в виде лишения свободы : автореф. дис. ... д-ра юрид. наук. М., 2000. 39 с.

10. Лебедев В. М. Проблемы становления и развития судебной власти в Российской Федерации : дис. ... д-ра юрид. наук. М., 2000. С. 177.

11. Руднев В. Пенитенциарный судья. К вопросу о судебном контроле за исполнением наказаний // Российская юстиция. 2001. № 8. С. 32- 34.

12. Давыљов Д. А. Понятие и содержание судебного контроля за деятельностью персонала учреждений и органов, исполняющих наказания // Вестник Московского университета МВД России. 2011. № 5. 149-151.

13. Давыљова И. А. Направления судебной деятельности, связанные с исполнением уголовных наказаний: проблемы отраслевой принадлежности // Вестник Кузбасского института. 2018. № 3. С. 134-143. 
14. Крымов А. А. Особенности принятия процессуальных решений в стадии исполнения приговора // Труды Академии управления МВД России. 2015. № 2. С. 18-21.

15. Шашкова А. В. Проблемы и принципы функционирования судебной системы Испании // Социально-политические науки. 2018. № 1. С. 33-36.

16. Лебедевич Д. Данные о личности осужденного как основной вопрос при рассмотрении ходатайств об условно-досрочном освобождении // Законность. 2009. № 5. С. 46-48.

1. Kashuba, Yu. A., Skiba, A. P. (2011) Releaseon parole: newviews // Man: crime and punishment. $1,14-17$.

2. Razgildiev, B. T. (2015) Criminal-law prevention of illicit trafficking drugs and psychotropic substances, types and criteria of realization // Criminal and legal prevention in the sphere of trafficking in narcotic drugs or psychotropic substances, alcoholic and alcohol-containing products (regional aspect) : collection of materials of the All-Russian scientific and practical conference (Cheboksary, April 17, 2015). Cheboksary: Chuvash University Press, pp. 250-260.

3. Efremova, I. A. (2018) The material basis for the early conditional release from punishment // Russian Journal of Criminology. V. 12, 1, 82-91.

4. Knyazkov, A. S., Utkin, V. A. (2015) Release on parole in case of life imprisonment // Tomsk State University Journal of Law. 4, 45-53.

5. Savelyev, D. V. (2020) Grounds and conditions for exemption from criminal liability and punishment : textbook for universities. Moscow : Yurait, p. 191.

6. Babayan, S. L. (2017) Application of the incentive of release on parole // Vestnik of Moscow State Linguistic University. Education and teaching. 3, 142-149.

7. Davydova, I. A., Korobova, I. N. (2017) On issue of the institution of parole effectiveness // Bulletin of the penal system. 12, 20-25.

8. Myakhanova, A. N., Sinkov, D. V. (2018) The question of corruption during releasement on parole // Bulletin of the Omsk Law Academy. V. 15, 3, 292-297.

9. Epaneshnikov, V. S. (2000) Legal responsibility of persons serving a sentence of imprisonment: thesis ... of Dr. of Law. Moscow, 39 p.

10. Lebedev, V. M. (2000) Problems of the formation and development of the judiciary power in the Russian Federation : thesis ... of Dr. of Law. Moscow, p. 177.

11. Rudnev, V. (2001) Penitentiary judge. On the issue of judicial control over the execution of sentences // Russian justice. 8, 32-34.

12. Davydov D. A. (2011) The concept and content of judicial control over the prison staff // Vestnik of Moscow University of the Ministry of Internal Affairs of Russia. 5, 149-151.

13. Davydova, I. A. (2018) Directions of judicial activity related to criminal performance: problems of sectoral accessories // Bulletin of the Kuzbass Institute. 3, 134-143.

14. Krymov, A. A. (2015) Procedural decision making specifics at the sentence execution stage // Proceedings of Management Academy of the Ministry of the Interior of Russia. 2, 18-21.

15. Shashkova, A. V. (2018) Problems and principles of the Spanish system of justice // Sociopolitical sciences. 1, 33-36.

16. Lebedevich, D. (2009) Data on the convict identity as the main issue when considering applications for parole // Legality. 5, 46-48. 